\title{
Evaluation of biopreservatives in Greek yogurt to inhibit yeast and mold spoilage and development of a yogurt spoilage predictive model
}

\author{
A. J. Buehler, N. H. Martin, K. J. Boor, and M. Wiedmann ${ }^{1}$ \\ Milk Quality Improvement Program, Department of Food Science, Cornell University, Ithaca, NY 14853
}

\begin{abstract}
Dairy products, including cultured dairy products such as cheese and yogurt, are susceptible to fungal spoilage. Traditionally, additives such as potassium sorbate have been used to control fungal spoilage; however, with consumer demand for clean-label products, other strategies to control fungal spoilage (e.g., biopreservatives) are increasingly being used in dairy formulations. In order to help the dairy industry better evaluate biopreservatives for control of fungal spoilage, we developed a challenge study protocol, which was applied to evaluate 2 commercially available protective cultures for their ability to control yeast and mold spoilage of Greek yogurt. Greek yogurt formulated with and without protective cultures was inoculated with a cocktail consisting of 5 yeasts and 1 mold to yield inoculum levels of $10^{1}$ and $10^{3} \mathrm{cfu} / \mathrm{g}$ of yogurt. The inoculated yogurts were stored at $7^{\circ} \mathrm{C}$ and fungal counts as well as time to visible growth, on the yogurt surface, of mycelium mold colonies or yeast were determined over shelf-life. Whereas fungal concentrations increased to spoilage levels $\left(\geq 10^{5} \mathrm{cfu} / \mathrm{g}\right)$ in all yogurt formulations at both inoculum levels by d 23 of storage at $7^{\circ} \mathrm{C}$, no surface mold was observed over $76 \mathrm{~d}$ in any of the products formulated with protective cultures. Control yogurts without biopreservatives all showed surface mold by d 23. In order to allow industry to better evaluate the business effects of improved control of surface mold growth that can be achieved with protective cultures, we developed a Monte Carlo simulation model to estimate consumer exposure to visible mold growth in yogurt formulated without fungal inhibitors. Our model showed that initial mold contamination rate has the largest effect on the model outcome, indicating that accurate data on contamination rates are important for use of these models. When air plates
\end{abstract}

Received May 18, 2018.

Accepted August 6, 2018.

${ }^{1}$ Corresponding suthor: mw16@cornell.edu were used, in a proof-of-concept approach, to estimate initial contamination rates in a small yogurt manufacturing operation, our model predicted that $550 \pm 25.2$ consumers ( \pm standard deviation) would be exposed to visible mold growth for every 1 million cups of yogurt produced. With initial contamination rate data for individual facilities, this model could be used by industry to estimate the number of consumers exposed to visible mold spoilage and could allow industry to better assess the value of mold-control strategies.

Key words: protective culture, yeast, mold, yogurt

\section{INTRODUCTION}

Fungal spoilage of food accounts for an estimated 5 to $10 \%$ of food loss worldwide (Pitt and Hocking, 2009). Dairy products, including cultured dairy products such as cheese and yogurt, are susceptible to fungal spoilage (Suriyarachchi and Fleet, 1981; Kure et al., 2004; Ledenbach and Marshall, 2009; Garnier et al., 2017a). Fungal contamination can occur throughout the dairy processing continuum, from the dairy farm environment to the finished product-processing environment (Kure et al., 2001; Temelli et al., 2006; Vacheyrou et al., 2011). Although it has been reported that raw milk is a source for natural fungal contaminants (Lavoie et al., 2012; Atanassova et al., 2016; Buehler et al., 2017), these organisms are typically not heat resistant and thus not the main route for fungal contamination of dairy products (Jacques and Casaregola, 2008; Garnier et al., 2017b). The processing environment, specifically after pasteurization, represents the most common source for fungal contamination of dairy products. Moreover, the processing facility air is a common transmission route for fungal contaminants (Temelli et al., 2006; Beletsiotis et al., 2011; Radha and Nath, 2014). For example, during a 1-yr prospective study of fungal air contamination in a yogurt plant in Greece, the molds Penicillium spp. and Cladosporium spp. represented the most commonly isolated species from the plant's indoor air samples (Beletsiotis et al., 2011). Yeast contamination can also be airborne (Beletsiotis et al., 2011), but more often originates from surfaces, supplier ingredients (e.g., fruit 
preparations), and the production environment (Penney et al., 2004; Mayoral et al., 2005; Bokulich and Mills, 2013).

Traditional methods for controlling fungal spoilage of yogurt include using food additives such as potassium sorbate (Davidson et al., 2013). As consumers demand clean-label food products, however, the food industry is challenged to produce the same quality products with the same shelf-life without the use of traditional food additives (Zink, 1997; Devlieghere et al., 2004). One way to achieve a clean-label food product with a similar shelf-life to traditional products is through the use of biopreservatives (Schnürer and Magnusson, 2005; Crowley et al., 2013b). Biopreservatives are defined as added microorganisms or their metabolites, or the combination of both, that aid in shelf-life extension of food (Holzapfel et al., 1995). Examples of biopreservatives include lactic acid bacteria (e.g., protective cultures), bacteriocins, and natural enzyme systems (e.g., lactoperoxidase; Stiles, 1996). The use of protective cultures, in particular, has been applied to many food sectors, such as baking (Gerez et al., 2009; Muhialdin et al., 2011; Garofalo et al., 2012), dairy (Delavenne et al., 2013; Cheong et al., 2014), and fruits and vegetables (Sathe et al., 2007; Crowley et al., 2013a). In yogurt, in particular, research has focused on strain-specific fungal inhibition, using model yogurt systems; however, limited research exists on the use of protective cultures in Greek yogurt (Delavenne et al., 2013; Lačanin et al., 2017). Greek yogurt production differs from traditional Swiss-style yogurt production in that Greek yogurt is centrifugally separated to concentrate the curd and remove the acid whey following fermentation. Whereas the additional processing steps for Greek yogurt do not typically expose the product directly to the processing environment, a need for control strategies still exists to protect the product from fungal contamination during production, especially in filling and packaging, when the product is exposed to the processing environment. Including antifungal biopreservatives in the formulation could be one way to protect the product from fungal contamination in a way that is acceptable to consumers.

Estimates of yogurt spoilage due to fungal contamination have the potential to help yogurt producers determine and assess the effectiveness of quality interventions to protect their product. Stochastic modeling approaches have been used extensively in food safety applications, most often to estimate mean illness cases per year following consumption of a particular contaminated food [e.g., listeriosis cases from deli meats (Pradhan et al., 2009, 2010), illness cases from consumption of fresh-cut lettuce contaminated with Escherichia coli
O157:H7 (Pang et al., 2017), and salmonellosis cases from consumption of pistachios (Lambertini et al., 2017)]; however, stochastic modeling approaches have been applied to dairy quality less frequently, with only a few models focusing on fluid milk spoilage (Schaffner et al., 2003) and yogurt spoilage (Gougouli and Koutsoumanis, 2017). A recent study (Gougouli and Koutsoumanis, 2017) reported a simulation model that estimated the time to visible mold growth; however, this model did not account for variation in the initial contamination rate. Whereas estimates of initial fungal contamination rate at the processing facility may be difficult to obtain, a need exists for a baseline understanding of these values to inform spoilage control strategies and to accurately predict the number of consumers exposed to visible mold growth in yogurt. In addition, there is a need to develop and use simulation models to allow for quantitative assessment of intervention strategies, such as protective cultures, before implementation. Thus, the objectives of our study were to (1) evaluate the effectiveness of protective cultures to inhibit yeast and mold growth in yogurt and (2) develop a baseline stochastic model to estimate consumer exposure to yogurt with visible mold growth when no fungal inhibitor is employed in the yogurt formulation.

\section{MATERIALS AND METHODS}

\section{Isolate Selection}

Based on the isolates characterized in Buehler et al. (2017) and information listed in Food Microbe Tracker (www.foodmicrobetracker.com; Vangay et al., 2013), 6 isolates were selected to represent a broad range of dairy-relevant fungal spoilage organisms. The selected isolates represent 5 yeast organisms and 1 mold organism (Table 1). Identification of yeast isolates to the species level and the mold isolate to the genus level was completed in a previous study and was based on internal transcribed spacer (ITS) sequencing (Buehler et al., 2017). The mold isolate was identified to species level by phenotypic classification according to Frisvad and Samson (2004).

\section{Cocktail Preparation}

The 5 yeast organisms (Candida parapsilosis, Clavispora lusitaniae, Kloeckera apiculata, Metschnikowia pulcherrima, and Torulaspora delbrueckii) were streaked for isolation on dichloran rose bengal chloramphenicol agar (DRBC; Becton, Dickinson and Co., Sparks, MD), followed by incubation at $25^{\circ} \mathrm{C}$ for $72 \mathrm{~h}$. Single yeast colonies were inoculated into $9 \mathrm{~mL}$ of malt extract broth 
Table 1. Genus and species identification, isolation source, and internal transcribed spacer (ITS) allelic type (AT) for the 6 study isolates

\begin{tabular}{lllrr}
\hline Genus & Species & FSL ID & Source & ITS AT \\
\hline Candida & parapsilosis & E2-0454 & Yogurt & 30 \\
Clavispora & lusitaniae & E2-0451 & Yogurt & 61 \\
Kloeckera & apiculata & E2-0456 & Yogurt & 99 \\
Metschnikowia & pulcherrima & E2-0608 & Yogurt & 135 \\
Penicillium & commune & E2-0427 & Yogurt & 9 \\
Torulaspora & delbrueckii & E2-0444 & Yogurt & 60 \\
\hline
\end{tabular}

${ }^{1}$ FSL ID = Cornell University Food Safety Lab isolate designation.

(MEB; Becton, Dickinson and Co.), followed by incubation at $30^{\circ} \mathrm{C}$ in a shaking incubator (New Brunswick Scientific, Edison, NJ) at $140 \mathrm{rpm}$ for $48 \mathrm{~h}$. Yeast were then enumerated by spiral plating on DRBC using an Autoplate 5000 (Advanced Instruments Inc., Norwood, MA). The DRBC plates were incubated at $25^{\circ} \mathrm{C}$ for 72 h. Following incubation, colonies were counted with the QCount Automated Colony Counter (Advanced Instruments Inc.). Inoculated MEB solutions were stored at $4^{\circ} \mathrm{C}$ until cultures were enumerated.

The mold isolate, Penicillium commune, was streaked for isolation on DRBC, followed by incubation at $25^{\circ} \mathrm{C}$ for $72 \mathrm{~h}$. To prepare a $P$. commune mycelium suspension, $5 \mathrm{~mL}$ of PBS (Weber Scientific, Hamilton, NJ) was added to the DRBC plate and a sterile inoculation loop was used to dislodge mycelium growth into the PBS. A sterile cotton swab was then used to collect approximately half of the mycelium suspension and subsequently inoculate a lawn on a DRBC plate, which was then incubated at $25^{\circ} \mathrm{C}$ for $72 \mathrm{~h}$. Following incubation, the mycelium growth was harvested into $5 \mathrm{~mL}$ of PBS, as described above, and used for preparation of the cocktail. The concentration of $P$. commune in the harvested mycelium suspension was estimated based on enumeration of $P$. commune mycelium suspensions from the initial DRBC plate and was confirmed after preparation of the cocktail. For enumeration, mycelium suspensions were serially diluted in PBS and spread plated on $\mathrm{DRBC}$, followed by incubation at $25^{\circ} \mathrm{C}$ for 72 h. Colonies were counted with the QCount Automated Colony Counter (Advanced Instruments Inc.).

Two cocktails were prepared to achieve final concentrations of $10^{1}$ and $10^{3} \mathrm{cfu}$ of yeast and mold per gram of yogurt. To prepare the $10^{1} \mathrm{cfu} / \mathrm{g}$ of yogurt inoculum, after each individual yeast and mold solution had been quantified, each solution was diluted in PBS to reach a concentration of $1.7 \times 10^{4} \mathrm{cfu} / \mathrm{mL}$. To prepare the $10^{3} \mathrm{cfu} / \mathrm{g}$ of yogurt inoculum, each solution was diluted in PBS to reach a concentration of $1.7 \times 10^{6} \mathrm{cfu} / \mathrm{mL}$. The individual diluted solutions were then blended together in equal amounts to create the final cocktails. The cocktails were used within $2 \mathrm{~h}$ after blending. Both final cocktails were enumerated on DRBC to ensure the target concentration was achieved.

\section{Preparation of Greek Yogurt}

Plain, nonfat Greek yogurt was produced at Cornell University's Food Processing and Development Laboratory (Ithaca, NY). Commercially available Lactobacillus delbrueckii ssp. bulgaricus and Streptococcus thermophilus strains, as well as commercially available protective cultures, were used in fermentation. Two protective cultures, A and B, were evaluated independently at 3 concentrations in the yogurt formulation: (1) the manufacturer's recommended concentration $(100 \%$ A, $100 \%$ B), (2) $5 \%$ less than the manufacturer's recommended concentration (95\% A, 95\% B), and (3) 10\% less than the manufacturer's recommended concentration $(90 \%$ A, $90 \%$ B). Both protective cultures used contain lactic acid bacteria (Lactobacillus). The following yogurt formulations were prepared: (1) a control (with no protective culture), (2) 3 batches of yogurt with protective culture A at the 3 levels mentioned above, and (3) 3 batches of yogurt with protective culture $\mathrm{B}$ at the 3 levels mentioned above. The yogurt was separated, using a centrifugal separator, to $9.5 \%$ protein after the fermented product reached a $\mathrm{pH}$ in the range of 4.55 to 4.70. Following separation, the product was filled into 6 -oz cups, sealed with a foil lid, and cooled to $4^{\circ} \mathrm{C}$. The product was then stored at $4^{\circ} \mathrm{C}$ until inoculation, for a maximum of $4 \mathrm{~d}$.

\section{Inoculation and Subsequent Enumeration of Greek Yogurts}

Yogurts were inoculated with $100 \mu \mathrm{L}$ of a yeast and mold cocktail (for final concentrations of $10^{1}$ or $10^{3}$ $\mathrm{cfu} / \mathrm{g}$ of yogurt) or sterile PBS (negative control) from the bottom of the cup with a sterile 20-gauge needle to ensure the headspace of the yogurt remained intact. The needle was inserted to approximately the upper third (closest to the exposed yogurt surface, near the foil lid) of the cup, without penetrating the headspace. 
Immediately following inoculation, the hole produced from the needle was sealed with sterile, adhesive foil. The inoculated yogurts were then stored at $7^{\circ} \mathrm{C}$ until enumeration. Two yogurts of each formulation variable and inoculum concentration were enumerated on d 0 (inoculation day), 9, and 23. In addition, yogurts inoculated with $10^{1} \mathrm{cfu} / \mathrm{g}$ and sterile PBS were enumerated on d 60 and 76 . To enumerate the d 0, 9, 23, 60 , and 76 yogurts, yogurt samples were diluted 1:10 in PBS, followed by vigorous shaking for $10 \mathrm{~s}$. Each diluted yogurt sample was spread-plated directly on DRBC, followed by incubation at $25^{\circ} \mathrm{C}$ for $120 \mathrm{~h}$. For d 0 , one $100-\mathrm{mL}$ enrichment was prepared for each yogurt sample inoculated at $10^{1} \mathrm{cfu} / \mathrm{g}$, consisting of $90 \mathrm{~mL}$ of $\mathrm{MEB}$ and $10 \mathrm{~g}$ of yogurt. Enrichments were prepared in sample bags and homogenized at $260 \mathrm{rpm}$ for $60 \mathrm{~s}$ in a Stomacher 400 Circulator (Seward Ltd., West Sussex, United Kingdom) and incubated at $25^{\circ} \mathrm{C}$ for $72 \mathrm{~h}$. Following incubation, enrichments were spread-plated on DRBC followed by another incubation at $25^{\circ} \mathrm{C}$ for 120 h. A QCount Automated Colony Counter (Advanced Instruments Inc.) was used to enumerate colonies.

\section{Time to Visible Fungal Growth}

Time to visible fungal growth was visually estimated by opening 2 yogurts inoculated at $10^{1} \mathrm{cfu} / \mathrm{g}$ yogurt of each yogurt formulation on d $0,9,23$, and then every 3 $\mathrm{d}$ from d 34 to 76 of incubation at $7^{\circ} \mathrm{C}$. Briefly, the foil lid was removed from the cup, and the yogurt surface was visually inspected for fungal growth (either mycelium colonies or yeast). A picture of the surface of the sample was taken before discarding the sample.

\section{Model Development}

Model Assumptions. In this model, all of the initial mold contamination in the yogurt was assumed to be the mold $P$. commune. Previous studies of fungal diversity have found that $P$. commune is frequently isolated from the yogurt production facility (Gougouli et al., 2011; Buehler et al., 2017). Growth of P. commune was adjusted for changes in storage temperature over time by assuming instantaneous adaptation of growth rate when temperature changed; lag phase was cumulative over storage time, similar to previous approaches (Koutsoumanis, 2001; Gougouli and Koutsoumanis, 2010). The base model used parameters typical for a nationally distributed yogurt in the United States.

Model Parameters. A simulation model estimating the number of yogurt cups with visible $P$. commune growth when opened was programmed in $\mathrm{R}$ v. 3.3.2 (R Core Team, 2013). Model parameters included initial contamination rate $\left(\mathbf{C}_{0}\right)$, time from production to retail $\left(\mathbf{S}_{\mathbf{R}}\right)$, retail case storage time $\left(\mathbf{S}_{\mathrm{C}}\right)$, domestic refrigerator storage time $\left(\mathbf{S}_{\mathbf{D}}\right)$, storage temperature from production to consumer purchase $\left(\mathbf{T}_{\mathbf{C}}\right)$, domestic refrigerator storage temperature $\left(\mathbf{T}_{\mathbf{D}}\right)$, mycelium growth rate as a function of temperature $\left(\boldsymbol{\mu}_{\mathrm{T}}\right)$, lag time as a function of temperature $\left(\boldsymbol{\lambda}_{\mathbf{T}}\right)$, mycelium colony diameter $\left(\mathbf{D}_{\mathbf{S}}\right)$, and visible mycelium colony to consumer $\left(\mathbf{V}_{\mathbf{C}}\right.$; Table 2$)$.

Initial contamination rate was estimated by collecting air-plate samples in the yogurt packaging room of the dairy plant at Cornell University (Ithaca, NY) according to Standard Methods for the Examination of Dairy Products (Dyer et al., 2004). Briefly, 2 DRBC plates were placed on the plexiglass guard of the yogurt filling and packaging machine, where yogurt was filled into cups; this location was deemed to represent the best proxy for air contamination that would be deposited into open yogurt cups. The plates were left uncovered for $15 \mathrm{~min}$ and then were covered and subsequently incubated at $25^{\circ} \mathrm{C}$ for $120 \mathrm{~h}$. This was repeated for 3 yogurt-processing days. These plates yielded 3 mold colonies over the $3 \mathrm{~d}$. As this represents $45 \mathrm{~min}(3 \mathrm{~d}$ $\times 15 \mathrm{~min} / \mathrm{d}$ ) of air exposure over the surface area of 2 plates, we estimated the contamination rate to be 3 mold spores per $45 \mathrm{~min}$ (or 1 spore per $15 \mathrm{~min}$ or 900 s). To determine the initial contamination rate, expert opinion was elicited to estimate the amount of time yogurt cups are exposed to air after being filled with product for a large-scale yogurt production operation. This value was estimated as $0.5 \mathrm{~s}$. With 1 mold spore deposition per $900 \mathrm{~s}$, this yields an estimate of 1 mold contamination event per 1,800 cups of yogurt.

Expert opinion was solicited to estimate the model parameters of $S_{R}, S_{C}$, and $S_{D}$. The $T_{C}$ was obtained from Pradhan et al. (2009), and $\mathrm{T}_{\mathrm{D}}$ was obtained from EcoSure $(2007) ; \mu_{\mathrm{T}}$ and $\lambda_{\mathrm{T}}$ were modeled using the cardinal model with inflection described by Rosso et al. (1993). Values for $\mu_{\mathrm{T}}$ and $\lambda_{\mathrm{T}}$ for P. commune in yogurt were obtained from Gougouli et al. (2011). The minimum colony size consumers can detect with a naked eye was defined as $3 \mathrm{~mm}$; this estimate has been used in previous studies (Gougouli et al., 2011; Burgain et al., 2013).

Model Simulations. The simulation model predicted the number of consumers exposed to visible mycelium growth in yogurt based on (1) the yogurt distribution chain, (2) storage temperatures from production to consumer purchase and during storage in domestic refrigerators, (3) initial mold contamination rates, and (4) growth characteristics of $P$. commune in yogurt. Each iteration resulted in a prediction of how many consumers were exposed to mycelium growth $\geq 3 \mathrm{~mm}$. The simulation of 1 million cups of yogurt 





contaminated, then distributed to consumers, stored in domestic refrigerators, and finally opened by consumers was repeated 100 times.

\section{Sensitivity Analysis}

A best- and worst-case scenario analysis was used to determine quantitatively the most important parameters affecting consumer exposure to visible mold in the model (Zwieterin and Van Gerwen, 2000). The effects of 8 major aspects of yogurt spoilage due to mold contamination were evaluated using a best- and worstcase scenario analysis. Best-case scenarios were defined as changes that would reduce consumer exposure to mold in yogurt (e.g., lower initial contamination rate), whereas worst-case scenarios were defined as changes that would increase consumer exposure to mold in yogurt. The 8 major aspects of mold contamination evaluated were (1) initial contamination rate, $\mathrm{C}_{0} ;(2)$ time from production to retail, $\mathrm{S}_{\mathrm{R}} ;(3)$ retail case storage time, $\mathrm{S}_{\mathrm{C}} ;$ (4) domestic refrigerator storage time, $\mathrm{S}_{\mathrm{D}} ;(5)$ domestic refrigerator storage temperature, $\mathrm{T}_{\mathrm{D}}$; (6) storage temperature from production to consumer purchase, $\mathrm{T}_{\mathrm{C}} ;(7)$ mycelium growth rate, $\mu_{\mathrm{T}}$; and (8) lag time, $\lambda_{\mathrm{T}}$. For $\mathrm{C}_{0}$, the worst-case scenario was a 0.25 increase of the mean of the numerator to $1.25 / 1,800$ (low) and a 0.5 increase of the mean of the numerator to $1.5 / 1,800$ (high); the best-case scenario was a 0.25 decrease of the mean of the numerator to $0.75 / 1,800$ (low) and 0.5 decrease of the mean of the numerator to $0.5 / 1,800$ (high). For $\mathrm{S}_{\mathrm{R}}, \mathrm{S}_{\mathrm{C}}$, and $\mathrm{S}_{\mathrm{D}}$, the worst-case scenarios were defined as a 20\% (low) and 40\% (high) increase in storage time; the best-case scenarios were defined as a 20\% (low) and 40\% (high) decrease in storage time. For $\mathrm{T}_{\mathrm{D}}$, the worst-case scenarios were calculated by increasing the temperature mean by 1 (low) and $2^{\circ} \mathrm{C}$ (high); the best-case scenarios were calculated by decreasing the temperature mean by 1 (low) and $2^{\circ} \mathrm{C}$ (high). For $\mathrm{T}_{\mathrm{C}}$, the worst-case scenarios were calculated by increasing the maximum temperature by 1 (low) and $2^{\circ} \mathrm{C}$ (high); the best-case scenarios were calculated by decreasing the maximum temperature by 1 (low) and $2{ }^{\circ} \mathrm{C}$ (high). For $\mu_{\mathrm{T}}$, the worst-case scenarios were a $20 \%$ (low) and $40 \%$ (high) increase; the best-case scenarios were a $20 \%$ (low) and $40 \%$ (high) decrease. For $\lambda_{\mathrm{T}}$, the worst-case scenarios were a $20 \%$ (low) and $40 \%$ (high) decrease; the best-case scenarios were a $20 \%$ (low) and $40 \%$ (high) increase. Best- and worst-case sensitivities were calculated as the difference between the number of consumers opening yogurt with visible mold growth for each aspect above independently and the baseline model, where all 8 aspects were set to their original values. Ultimately, this sensitivity analysis helped to identify which model parameters have the most influ- ence on whether a consumer opens a cup of yogurt with visible mold growth.

\section{What-If Analysis}

Two what-if scenarios were used to demonstrate the effect of the distribution chain and interventions yogurt processors and consumers might employ to reduce the number of yogurt cups with visible mold growth: having a regional distribution chain and lowering the storage temperature. For scenario 1, a regional yogurt producer was surveyed to obtain estimates of a regional distribution chain. Time from production to retail was modeled with a triangle distribution with a minimum of $24 \mathrm{~h}$, maximum of $168 \mathrm{~h}$, and most likely value of $120 \mathrm{~h}$. The time that yogurt cups were at a retail facility until purchased by consumers was modeled with a triangle distribution with a minimum of $24 \mathrm{~h}$, maximum of 672 $\mathrm{h}$, and most likely value of $336 \mathrm{~h}$.

For scenario 2, the storage temperature was lowered, applied in combination by (1) reducing the mean domestic refrigerator temperature by $2^{\circ} \mathrm{C}$ and (2) limiting the maximum storage temperature during production to consumer purchase to $3^{\circ} \mathrm{C}$.

\section{Statistical Analysis}

All statistical analysis was performed in $\mathrm{R}$ v. 3.3 .2 ( $\mathrm{R}$ Core Team, 2013). Microbiological count data were log-transformed before performing analyses on fungal numbers by day of shelf-life. Count data were analyzed separately by final inoculum level (either $10^{1}$ or $10^{3}$ cfu/g of yogurt). A two-way ANOVA for each inoculum level $\left(10^{1}\right.$ or $\left.10^{3} \mathrm{cfu} / \mathrm{g}\right)$ was used to assess the effects of protective culture use, day of shelf-life, and the interaction between protective culture use and day of shelflife. The data for yogurts formulated with protective cultures (protective culture count) were standardized to the mean of the control count by inoculum level (either $10^{1}$ or $10^{3} \mathrm{cfu} / \mathrm{g}$ ) for each day of shelf-life by taking the $\log$ of the ratio of the protective culture count (cfu/g) to the mean of the control count (cfu/g). The standardized count served as the response.

\section{RESULTS AND DISCUSSION}

In order to improve industry's ability to control yeast and mold spoilage in yogurt, we developed a challenge study protocol that was used to evaluate yeast and mold growth in yogurts formulated with and without protective cultures and challenged with yeast and mold cocktails, simulating low $\left(10^{1} \mathrm{cfu} / \mathrm{g}\right.$ of yogurt $)$ and high $\left(10^{3} \mathrm{cfu} / \mathrm{g}\right.$ of yogurt) levels of postpasteurization fungal contamination. This challenge study indicated that the 
2 commercially available protective cultures evaluated controlled surface mold growth, but not yeast growth over $76 \mathrm{~d}$ of yogurt shelf-life at $7^{\circ} \mathrm{C}$. In yogurts formulated without protective cultures, surface mold growth was visible within $23 \mathrm{~d}$ of storage. A predictive model was then developed to determine consumer exposure to visible mold in yogurt formulated without fungal inhibitors. Whereas this model provides a tool that can be used by individual facilities to predict consumer exposure to visible mold growth, plant-specific data, particularly with regard to initial mold contamination frequency, will be required for accurate assessment of mold growth. Combined, the data and tools presented here can be used to facilitate improved control of fungal spoilage in yogurt and allow industry to better assess the value and effect of different control strategies aimed at reducing yogurt spoilage due to yeasts and molds.

\section{Protective Cultures Control Surface Mold Growth But Not Yeast Growth Over 76 d}

In order to develop a challenge study protocol, we inoculated Greek yogurt, formulated with and without protective cultures, with a yeast and mold cocktail (containing 5 yeast and 1 mold strain) at final concentrations of $10^{1}$ and $10^{3} \mathrm{cfu} / \mathrm{g}$ of yogurt. When incubated at a mild abuse temperature of $7^{\circ} \mathrm{C}$, yogurt with no protective cultures inoculated with $10^{1} \mathrm{cfu}$ of yeast and mold per gram showed mean total yeast and mold numbers of $4.7 \log _{10} \mathrm{cfu} / \mathrm{g}$ at $\mathrm{d} 9$, with numbers between 4.9 and $6.5 \log _{10} \mathrm{cfu} / \mathrm{g}$ observed on d 23, 60, and 76 (Figure 1). From a practical standpoint, yeast spoilage of yogurt is noticeable when counts reach $10^{5}$ to $10^{6} \mathrm{cfu} / \mathrm{g}$ (Suriyarachchi and Fleet, 1981); hence, in our model, Greek yogurt reached spoilage levels of yeast and mold by d 23 of storage at $7^{\circ} \mathrm{C}$, well short of the 45 to $60 \mathrm{~d}$ target shelf-life typical for large US yogurt manufacturers. For the Greek yogurt formulations inoculated at $10^{3} \mathrm{cfu} / \mathrm{g}$ of yogurt, growth to spoilage levels $\left(10^{5}-10^{6}\right.$ $\mathrm{cfu} / \mathrm{g}$ ) occurred by d 9 at a storage temperature of $7^{\circ} \mathrm{C}$ (Figure 1). Visible surface mold growth was evaluated for yogurts inoculated at $10^{1} \mathrm{cfu} / \mathrm{g}$ of yogurt and revealed that, for yogurts formulated without protective cultures, visible mycelium growth occurred by d 23 of storage at $7^{\circ} \mathrm{C}$, whereas yogurts formulated with protective cultures, at all usage levels (i.e., 90, 95, and $100 \%$ of the manufacturer's recommended concentration), only displayed yeast growth over the entire 76-d shelf-life. Although we appreciate that the reduction of protective cultures to 95 and $90 \%$ represents a minimal reduction that would not even require a single doubling cycle to compensate for, even reductions such as these could represent significant savings for industry. However, in future work larger reductions (e.g., 75\%, if not
$50 \%$ ) should be evaluated. Moreover, for future efforts, our data suggest that a single low-level inoculum (e.g., $10^{1} \mathrm{cfu} / \mathrm{g}$ or possibly lower) is sufficient for challenge study protocols. Whereas previous challenge studies for mold used surface inoculation with mold spores (Delavenne et al., 2013; Lačanin et al., 2017), our data suggest that, at least for plain yogurt, spoilage due to mold surface growth can also be assessed by inoculating with a sterile needle into the bottom of closed yogurt cups, reaching the upper third of the product, closest to the foil lid and headspace of the product. Our needle inoculation method could also be applied to other yogurt formulations and could potentially even be used to target specific areas in the yogurt. For example, fruiton-the-bottom yogurt varieties typically have a highsugar fruit preparation at the base of the yogurt cup (Chandan and O'Rell, 2013). Needle inoculation could be used to directly inject spoilage organisms into the fruit and yogurt interphase to investigate contamination through added ingredients; however, further work would be needed to test this approach.

On d 9, fungal numbers in yogurt inoculated at $10^{1}$ $\mathrm{cfu} / \mathrm{g}$ and formulated with protective cultures (at 90, 95, and $100 \%$ of the recommended level) showed between 0.57 and $1.3 \log$ lower counts as compared to yogurt formulated without protective cultures; no significant differences were seen between protective cultures $\mathrm{A}$ and $\mathrm{B}$ and different use levels (Table 3). For d 23, 60, and 76, counts for products formulated with protective cultures $\mathrm{A}$ and B (across use levels) were generally numerically higher than counts for the control without protective cultures (except for 1 sample, the difference was always less than $1 \log )$; only 2 samples with protective cultures showed minimally lower counts $(0.05$ and $0.11 \mathrm{log})$. The effect of protective culture use, day of shelf-life, and the interaction between protective culture use and day of shelf-life for yogurt samples inoculated with $10^{1}$ cfu of yeast and mold per gram were compared with a twoway ANOVA (Table 3). A nested F-test was performed to compare the full factorial model, with both day effects and protective culture effects, to the simple model with only day effects; the nested F-test statistic for this comparison was $1.20(P=0.3204)$. Overall, our data indicate that, at an inoculum level of $10^{1} \mathrm{cfu} / \mathrm{g}$, the protective cultures evaluated clearly had no effect on fungal counts on d 23 or after. Although a small effect on fungal counts earlier in shelf-life was observed, further experiments (with larger sample numbers) would be required to further test this,if this information is deemed relevant considering a common yogurt shelf-life of 45 to $60 \mathrm{~d}$.

For yogurt inoculated at $10^{3} \mathrm{cfu} / \mathrm{g}$, fungal counts were only assessed through d 23 , as all products formulated with protective cultures exceeded 4.9 and 5.9 
$\log _{10} \mathrm{cfu} / \mathrm{g}$ on $\mathrm{d} 9$ and 23, respectively. In addition, most products formulated with protective cultures showed visible spoilage (e.g., puffed containers) by d 23. Interestingly, for the yogurt samples inoculated at $10^{3} \mathrm{cfu} / \mathrm{g}$, the two-way ANOVA analysis (Table 4) indicated significant main effects for protective culture use, with a F-test statistic of $7.33(P<0.01)$, as well as for day of shelf-life, with a F-test statistic of $211.69(P<$ 0.01). Surprisingly, yogurt formulated with protective cultures (across different use levels) generally showed $>2$ log higher counts as compared to products without protective cultures. As it is unlikely that protective cultures enhance fungal (and specially yeast) growth, it is more likely that at these high inoculum levels interactions between yeast and mold affect yeast growth. For example, yeasts may show improved growth when mold growth is suppressed due to protective cultures (as observed here). Whereas these findings further support that high inoculum levels $\left(10^{3} \mathrm{cfu} / \mathrm{g}\right)$ do not provide a valuable model for evaluating antifungal biopreservatives, future experiments with pure yeast strains or yeast only cocktails may be valuable to further address this observation.

Although yogurts inoculated at $10^{3} \mathrm{cfu} / \mathrm{g}$ were only evaluated through d 23, yogurts inoculated at $10^{1} \mathrm{cfu} / \mathrm{g}$ were evaluated on d $0,9,23$, and then every $3 \mathrm{~d}$ from $\mathrm{d}$ 34 to 76 for visual appearance of surface mold growth. For the yogurts formulated without protective cultures, visual mycelium growth was first recorded on d 23 (in both yogurts opened); all 18 cups of yogurt formulated without protective cultures and sampled on subsequent time points also displayed mycelium growth on the surface. In contrast, yogurts formulated with either protective culture at any tested concentrations (i.e., 100, 95, and 90\%; 48 samples total) failed to display visible mycelium growth during the $76 \mathrm{~d}$ of observation;
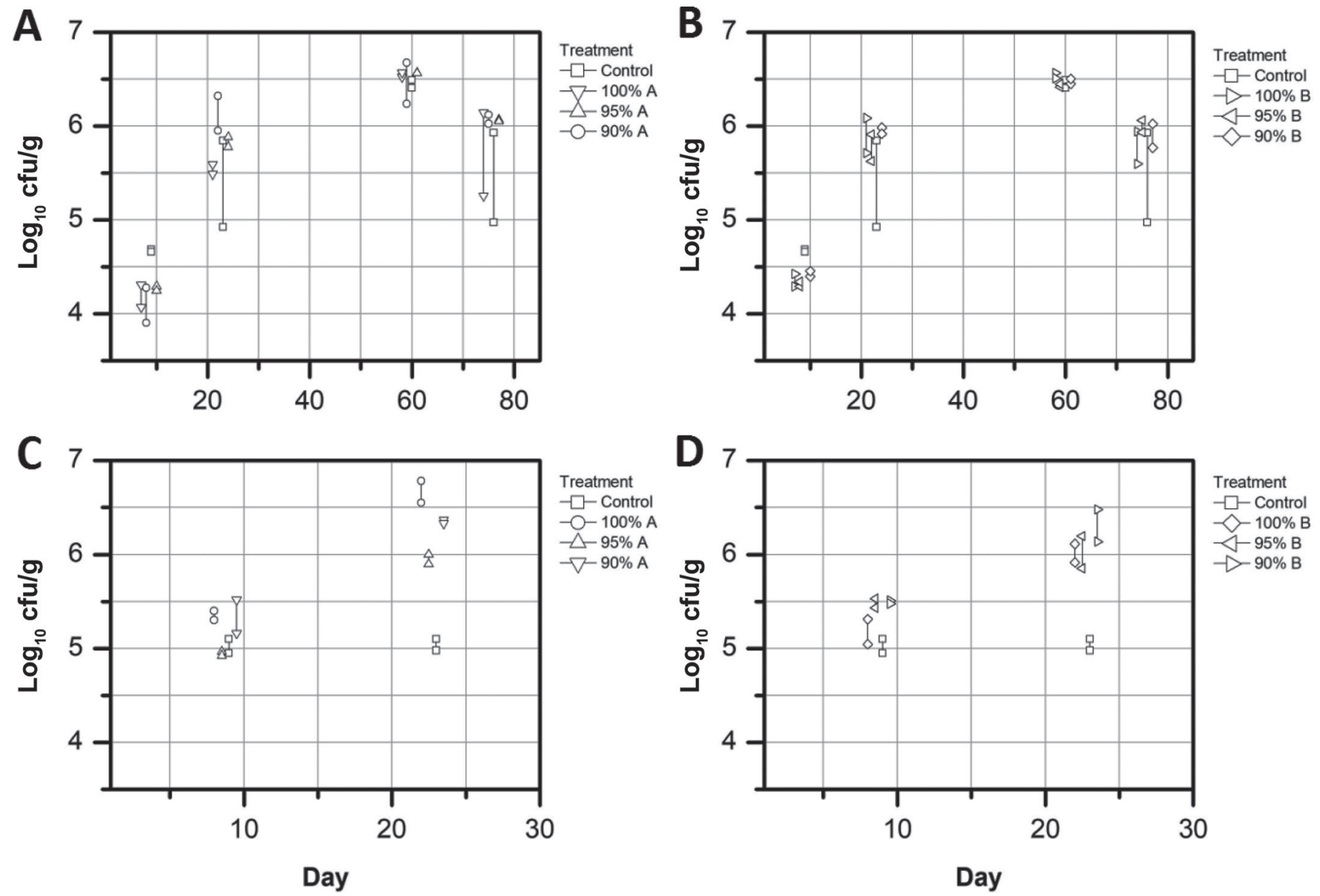

Figure 1. Concentration of yeast and mold in Greek yogurt by day of storage at $7^{\circ} \mathrm{C}$. Symbols represent yeast and mold concentrations for each cup of yogurt sampled. Two cups were sampled per treatment variable. Yogurts were inoculated with a cocktail consisting of 5 yeasts and 1 mold to yield inoculum levels of $10^{1}$ and $10^{3} \mathrm{cfu} / \mathrm{g}$ of yogurt. (A) Yogurts inoculated at $10^{1} \mathrm{cfu} / \mathrm{g}$ with and without protective culture A over 76 d. (B) Yogurts inoculated at $10^{1} \mathrm{cfu} / \mathrm{g}$ with and without protective culture B over $76 \mathrm{~d}$. (C) Yogurts inoculated at $10^{3} \mathrm{cfu} / \mathrm{g}$ with and without protective culture A over $23 \mathrm{~d}$. (D) Yogurts inoculated at $10^{3} \mathrm{cfu} / \mathrm{g}$ with and without protective culture B over $23 \mathrm{~d}$. 
Table 3. Protective culture and day effect on yeast and mold concentrations $\left(\log _{10} \mathrm{cfu} / \mathrm{g}\right)$ in Greek yogurt inoculated at $10^{1} \mathrm{cfu} / \mathrm{g}$ and stored at $7^{\circ} \mathrm{C}$ for $76 \mathrm{~d}$

\begin{tabular}{llcrr}
\hline & & & \multicolumn{2}{c}{ CI } \\
\cline { 3 - 5 } $\begin{array}{l}\text { Protective } \\
\text { culture }\end{array}$ & Day & $\begin{array}{c}\text { Mean difference } \\
\text { from control }\end{array}$ & Lower & Upper \\
\hline $100 \% \mathrm{~A}$ & 9 & $-1.11^{\mathrm{AB}}$ & -1.76 & -0.45 \\
$100 \% \mathrm{~B}$ & 9 & $-0.73^{\mathrm{ABCD}}$ & -1.38 & -0.08 \\
$95 \% \mathrm{~A}$ & 9 & $-0.93^{\mathrm{ABC}}$ & -1.59 & -0.28 \\
$95 \% \mathrm{~B}$ & 9 & $-0.82^{\mathrm{ABCD}}$ & -1.47 & -0.17 \\
$90 \% \mathrm{~A}$ & 9 & $-1.34^{\mathrm{A}}$ & -1.99 & -0.68 \\
$90 \% \mathrm{~B}$ & 9 & $-0.57^{\mathrm{ABCD}}$ & -1.22 & 0.09 \\
$100 \% \mathrm{~A}$ & 23 & $-0.11^{\mathrm{ABCDE}}$ & -0.76 & 0.54 \\
$100 \% \mathrm{~B}$ & 23 & $0.71^{\mathrm{BCDE}}$ & 0.06 & 1.36 \\
$95 \% \mathrm{~A}$ & 23 & $0.55^{\mathrm{BCDE}}$ & -0.10 & 1.20 \\
$95 \% \mathrm{~B}$ & 23 & $0.41^{\mathrm{ABCDE}}$ & -0.24 & 1.06 \\
$90 \% \mathrm{~A}$ & 23 & $1.26^{\mathrm{E}}$ & 0.61 & 1.91 \\
$90 \% \mathrm{~B}$ & 23 & $0.83^{\mathrm{CDE}}$ & 0.17 & 1.48 \\
$100 \% \mathrm{~A}$ & 60 & $0.23^{\mathrm{ABCDE}}$ & -0.43 & 0.89 \\
$100 \% \mathrm{~B}$ & 60 & $0.20^{\mathrm{ABCDE}}$ & -0.45 & 0.85 \\
$95 \% \mathrm{~A}$ & 60 & $0.26^{\mathrm{ABCDE}}$ & -0.39 & 0.91 \\
$95 \% \mathrm{~B}$ & 60 & $-0.05^{\mathrm{ABCDE}}$ & -0.70 & 0.61 \\
$90 \% \mathrm{~A}$ & 60 & $0.01^{\mathrm{ABCDE}}$ & -0.64 & 0.66 \\
$90 \% \mathrm{~B}$ & 60 & $0.06^{\mathrm{ABCDE}}$ & -0.59 & 0.71 \\
$100 \% \mathrm{~A}$ & 76 & $0.06^{\mathrm{ABCDE}}$ & -0.60 & 0.71 \\
$100 \% \mathrm{~B}$ & 76 & $0.22^{\mathrm{ABCDE}}$ & -0.43 & 0.87 \\
$95 \% \mathrm{~A}$ & 76 & $0.88^{\mathrm{CDE}}$ & 0.23 & 1.53 \\
$95 \% \mathrm{~B}$ & 76 & $0.75^{\mathrm{CDE}}$ & 0.09 & 1.40 \\
$90 \% \mathrm{~A}$ & 76 & $0.92^{\mathrm{DE}}$ & 0.27 & 1.57 \\
$90 \% \mathrm{~B}$ & 76 & $0.52^{\mathrm{BCDE}}$ & -0.14 & 1.17 \\
\hline
\end{tabular}

${ }^{\mathrm{A}-\mathrm{E}}$ Means with the same letter are not statistically different from each other (overall $\alpha=0.05$, Tukey's method for multiple comparisons).

${ }^{1}$ Results are summarized by the mean difference from control [ $\log _{10}$ (protective culture count/mean control count)] for 2 cups of yogurt sampled per treatment.

however, we noted visible indications of yeast growth (e.g., gas bubble production, off-white surface slime) on the surface of these yogurts (Figure 2). This finding

Table 4. Protective culture and day effect on yeast and mold concentrations $\left(\log _{10} \mathrm{cfu} / \mathrm{g}\right)$ in Greek yogurt inoculated at $10^{3} \mathrm{cfu} / \mathrm{g}$ and stored at $7^{\circ} \mathrm{C}$ for $23 \mathrm{~d}$

\begin{tabular}{|c|c|c|c|c|}
\hline \multirow{2}{*}{$\begin{array}{l}\text { Protective } \\
\text { culture }\end{array}$} & \multirow[b]{2}{*}{ Day } & \multirow{2}{*}{$\begin{array}{l}\text { Mean difference } \\
\text { from control }\end{array}$} & \multicolumn{2}{|c|}{ CI } \\
\hline & & & Lower & Upper \\
\hline $100 \% \mathrm{~A}$ & 9 & $0.74^{\mathrm{AB}}$ & 0.20 & 1.28 \\
\hline $100 \%$ B & 9 & $0.35^{\mathrm{A}}$ & -0.20 & 0.89 \\
\hline $95 \% \mathrm{~A}$ & 9 & $-0.20^{\mathrm{A}}$ & -0.74 & 0.35 \\
\hline $95 \% \mathrm{~B}$ & 9 & $1.04^{\mathrm{ABC}}$ & 0.50 & 1.59 \\
\hline $90 \% \mathrm{~A}$ & 9 & $0.72^{\mathrm{AB}}$ & 0.17 & 1.26 \\
\hline $90 \% \mathrm{~B}$ & 9 & $1.07^{\mathrm{ABC}}$ & 0.52 & 1.61 \\
\hline $100 \% \mathrm{~A}$ & 23 & $3.74^{\mathrm{E}}$ & 3.20 & 4.29 \\
\hline $100 \% \mathrm{~B}$ & 23 & $2.24^{\mathrm{CD}}$ & 1.70 & 2.78 \\
\hline $95 \% \mathrm{~A}$ & 23 & $2.09^{\mathrm{BCD}}$ & 1.54 & 2.63 \\
\hline $95 \% \mathrm{~B}$ & 23 & $2.27^{\mathrm{CD}}$ & 1.72 & 2.81 \\
\hline $90 \% \mathrm{~A}$ & 23 & $3.02^{\mathrm{DE}}$ & 2.47 & 3.56 \\
\hline $90 \% \mathrm{~B}$ & 23 & $2.92^{\mathrm{DE}}$ & 2.37 & 3.46 \\
\hline
\end{tabular}

\footnotetext{
${ }^{\mathrm{A}-\mathrm{E}}$ Means with the same letter are not statistically different from each other (overall $\alpha=0.05$, Tukey's method for multiple comparisons).

${ }^{1}$ Results are summarized by the mean difference from control [ $\log _{10}$ (protective culture count/mean control count)] for 2 cups of yogurt sampled per treatment.
}

suggests that increases in fungal counts in yogurts formulated without protective cultures represented both yeast and mold growth, whereas increased fungal numbers in yogurts with protective cultures were likely only due to yeast growth. Future improvements to time to visible growth measurements could be made by sealing containers with clear plastic lids instead of the foil lids used in our study. This could allow for the observation of time to visible growth without opening yogurt cups, and would likely improve estimations of time to visible growth, as yogurt cups could be monitored more frequently. Importantly, our time to visible growth measurements demonstrate that the 2 protective cultures, at all use levels we evaluated, were effective at inhibiting mycelium mold growth on the surface of the yogurt.

\section{Initial Mold Contamination Rate: Most Important Variable that Affects the Model}

In order to estimate the effects and benefits of different mold control strategies (such as protective cultures effective against mold), we developed a Monte Carlo simulation model to estimate how many consumers are exposed to visible mold in yogurt per 1 million cups produced. We elected to focus on modeling consumer exposure to visible mold, as this would allow industry to assess the value of using protective cultures that effectively inhibit mold growth. However, future efforts could use the model described here as a starting point to develop a similar model for yeast or yeast and mold growth in yogurt.

This model used 10 parameters to describe various aspects of the yogurt distribution chain (e.g., time from production to retail, consumer storage time, see Table 2 for details), assuming a national distribution chain with a 60-d shelf-life. Estimates for initial mold contamination rate were not available or accessible and were thus estimated by performing air plating for mold in a small commercial yogurt-production facility. These experiments yielded an estimate of 1 mold contamination event per 1,800 yogurt cups; this estimate was deemed realistic in discussions with industry. Another approach to estimate the initial mold contamination rate could be air sampling using an impaction onto agar method, with a commercially available rotary centrifugal air sampler, to measure colony-forming units per liter and subsequently convert to air flow (L/min) and exposure time (min). Although using the impaction onto agar method would capture molds present in the processing facility air, we elected to use air plates to estimate our initial mold contamination rate in order to capture the molds that settled at a specific location and a specific sized area. Whereas our initial mold contamination rate estimate was based on a small number of data 




Figure 2. Visible growth of yeast and mold on the surface of Greek yogurt inoculated with a cocktail consisting of 5 yeasts and 1 mold to yield an inoculum level of $10^{1} \mathrm{cfu} / \mathrm{g}$ and stored at $7^{\circ} \mathrm{C}$; growth was evaluated on days 34,48 , and 60 . Panels $\mathrm{A}, \mathrm{B}, \mathrm{I}, \mathrm{J}, \mathrm{Q}$, and R were formulated without protective cultures. Panels C, D, K, L, S, and T were formulated with $100 \%$ protective culture A. Panels E, F, M, N, U, and V were formulated with $95 \%$ protective culture A. Panels G, H, O, P, W, and X were formulated with $90 \%$ protective culture A. Color version available online. 


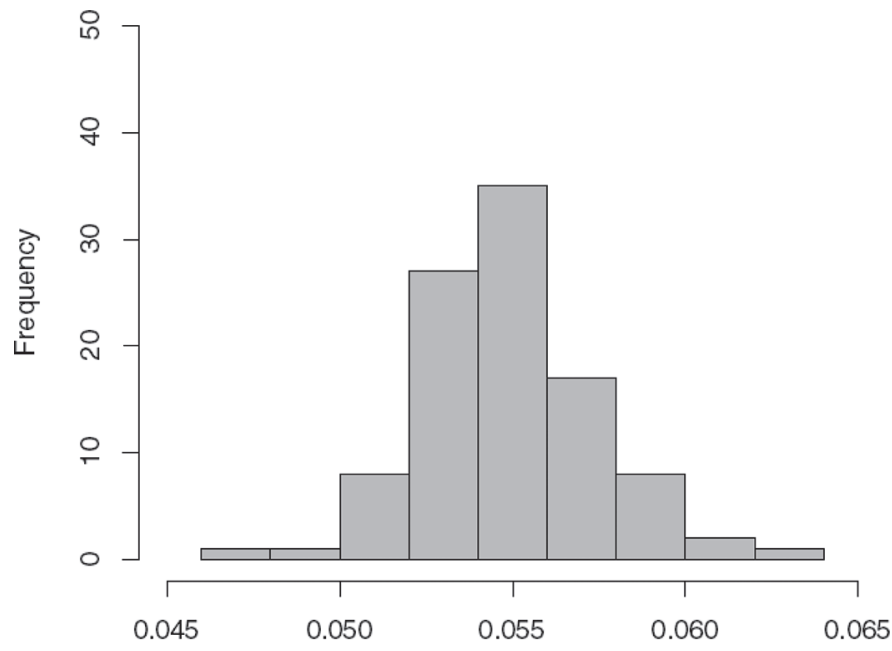

Percent of cups with visible mold

Figure 3. Histogram of the simulated percent of consumers exposed to visible mycelium mold growth per 1 million yogurt cups produced without the use of fungal inhibitors. Monte Carlo simulations comprised 100 iterations of 1 million cups of yogurt and were based on 10 model parameters: (1) initial mold contamination rate in the production facility, (2) time from production facility to retail facility, (3) retail case storage time, (4) domestic refrigerator storage time, (5) temperature from production to consumer purchase, (6) temperature during domestic refrigerator storage, (7) lag time of Penicillium commune as a function of temperature, (8) mycelium growth rate of $P$. commune as a function of temperature, (9) mycelium colony diameter as a function of stage of supply chain, and (10) visible mycelium growth to consumer.

collected in a single facility, this approach allowed us to develop a proof-of-concept Monte Carlo simulation model to estimate consumer exposure to visible mold contamination in yogurt. The Monte Carlo simulation model using this initial contamination rate, along with the other parameters detailed in Table 2, yielded an estimate of $550 \pm 25.2$ consumers $( \pm \mathrm{SD})$ that would be exposed to visible mold on the surface of yogurt per 1 million cups produced (Figure 3 ).

As this simulation approach can be used to estimate the number of consumers that will likely be exposed to visible mold growth in yogurt under a set of (current) production practices, it can also be used to help processors assess the value of spoilage control strategies by estimating the reduction of consumer exposures to mold that can be achieved with different interventions. Ultimately, the value of this model for processors could be improved if the model could be refined to include as an output the number of mold-related consumer complaints per 1 million cups produced. However, future efforts are needed to understand the relationship between consumer complaints and consumer exposure to fungal spoilage in yogurt. Previous reports of consumer complaint behavior for food products indicate low rates of reporting dissatisfaction directly to the manufacturer (Quelch and Ash, 1980; Richins and Verhage, 1985). For example, a study in Canada surveyed consumers about relative satisfaction about food products purchased and found that whereas around $39 \%$ of consumers reported taking direct action after unsatisfactory purchase experience with a food product (e.g., returned product to store, complained to store), only $2 \%$ specifically contacted the manufacturer (Quelch and Ash, 1980), suggesting that only 1 out of 50 consumer exposures to visible mold may trigger a consumer complaint to the manufacturer. Complaint rates may have changed considerably with the advent of social media platforms, and a considerably larger proportion of direct consumer actions may now manifest as consumer complaints to the manufacturer. Future research on current consumer complaint behavior for food products would clearly be needed to help us and others to include consumer complaints as an outcome in yogurt spoilage and other simulation models.

Importantly, best- and worst-case sensitivity analyses revealed that the initial contamination rate is the most important parameter that drives the model outcome of consumers exposed to visible mold in yogurt (Figure 4). Best-case scenarios of $\mathrm{C}_{0}$ lowered the number of consumers exposed to visible mold in yogurt from $550 \pm 25.2$ in the baseline model to $411 \pm 21.1$ (low) and 275.11 \pm 16.9 (high). This finding is similar to other studies that also indicated the importance of initial contamination rate at the processing level (Samson et al., 2010; Snyder et al., 2016), which, along with our sensitivity analysis, highlights the importance of accurate baseline mold contamination rate estimates to allow for accurate estimates of consumer exposure to visible mold and the value of different mold-control strategies. Approaches to estimating initial mold contamination rates could include (1) air plating approaches, such as those described here, or (2) end of shelf-life or stress test observations for visible mold contamination in commercially packaged yogurt; the latter approach, however, would require large sample sizes (likely $>1,000$ cups) due to the low-level nature of mold contamination in most yogurt facilities (MacBean, 2009). Thus, air plate sampling to obtain initial mold contamination rates may represent the most feasible first step processors can take in understanding the baseline mold contamination rate on a facility-specific basis.

Best- and worst-case sensitivity analyses indicate that time from production to retail (which encompasses warehouse storage and transportation) was the next most sensitive parameter in the model. Best-case scenarios of $S_{R}$ lowered the number of consumers exposed to visible mold in yogurt from $550 \pm 25.2$ in the baseline model to $534 \pm 24.9$ (low) and $493 \pm 24.0$ (high). 


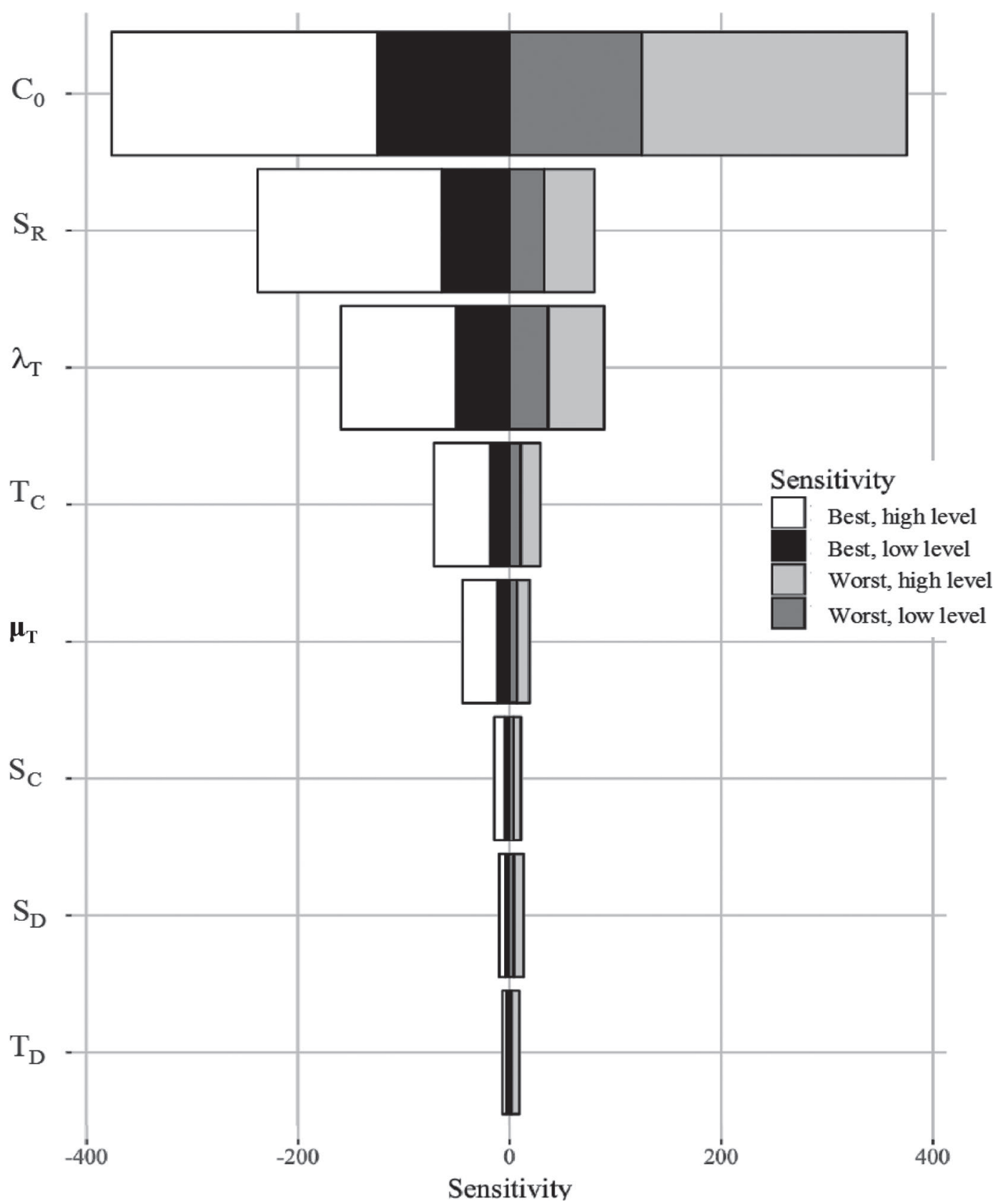

Figure 4. Best-case (white and black) and worst-case (gray) scenarios of the number of consumers exposed to visible mycelium mold ( $\geq 3$ $\mathrm{mm}$ ) in yogurt at the time of domestic consumption out of 1 million yogurt cups produced, using distribution parameters typical for a nationally distributed yogurt. Parameters displayed represent the most important factors affecting the estimated number of consumers exposed to visible mold. $\mathrm{C}_{0}$ represents the initial mold contamination rate; $\mathrm{S}_{\mathrm{R}}$ represents the time $(\mathrm{h})$ between yogurt manufacture at the production facility and arrival at the retail facility; $\lambda_{\mathrm{T}}$ (lag time) represents the time $(\mathrm{h})$ where the mycelium growth rate equals 0 ; $\mathrm{T}_{\mathrm{C}}$ represents the temperature from production to consumer purchase; $\mu_{\mathrm{T}}$ represents Penicillium commune mycelium growth rate; $\mathrm{T}_{\mathrm{D}}$ represents the temperature in the consumer's refrigerator; $S_{C}$ represents the time $(h)$ the yogurt cups stay at retail before being bought by the consumer; and $S_{D}$ represents the time (h) the yogurt cups are in the consumer's refrigerator before being opened. Best- and worst-case scenarios were calculated as the difference between the mean number of consumers exposed to visible mold when opening a cup of yogurt for each input value and the baseline model. Worst-case scenarios were calculated as a 0.25 (low) and 0.5 (high) increase of the numerator of the mean of $\mathrm{C}_{0} ; 20 \%$ (low) and $40 \%$ (high) increase of $\mathrm{S}_{\mathrm{R}}$, $\mathrm{S}_{\mathrm{C}}, \mathrm{S}_{\mathrm{D}}$, and $\mu_{\mathrm{T}} ; 20 \%$ (low) and $40 \%$ (high) decrease of $\lambda_{\mathrm{T}} ; 1^{\circ} \mathrm{C}$ (low) and $2^{\circ} \mathrm{C}$ (high) increase of the mean of $\mathrm{T}_{\mathrm{D}}$; and $1^{\circ} \mathrm{C}\left(\right.$ low) and $2^{\circ} \mathrm{C}$ (high) increase of the maximum value of $\mathrm{T}_{\mathrm{C}}$. Best-case scenarios were calculated similarly, with a 0.25 (low) and 0.5 (high) decrease of the numerator of the mean of $\mathrm{C}_{0} ; 20 \%$ (low) and $40 \%$ (high) decrease of $\mathrm{S}_{\mathrm{R}}, \mathrm{S}_{\mathrm{C}}, \mathrm{S}_{\mathrm{D}}$, and $\mu_{\mathrm{T}} ; 20 \%$ (low) and $40 \%$ (high) increase of $\lambda_{\mathrm{T}} ; 1^{\circ} \mathrm{C}$ (low) and $2^{\circ} \mathrm{C}$ (high) decrease of the mean of $\mathrm{T}_{\mathrm{D}}$; and $1^{\circ} \mathrm{C}$ (low) and $2^{\circ} \mathrm{C}$ (high) decrease of the maximum value of $\mathrm{T}_{\mathrm{C}}$. 
Table 5. Summary of what-if scenario analysis outcomes

Number of consumers exposed

to visible mold per 1 million

cups of yogurt produced

\section{What-if condition}

\begin{tabular}{cl} 
Mean & SD \\
\hline 550 & 25.2 \\
532 & 24.3 \\
538 & 25.9 \\
\end{tabular}

Initial condition

Regional distribution chain: $\mathrm{S}_{\mathrm{R}}{ }^{1}=$ triangle distribution $($ minimum $=24$, maximum $=168$, most likely $=120) ; \mathrm{S}_{\mathrm{C}}{ }^{2}=$ triangle distribution $($ minimum $=24$, maximum $=672$, most likely $=336)$

Lower storage temperature by (1) lowering the mean domestic refrigerator temperature by $2^{\circ} \mathrm{C}$

and (2) limiting the production to consumer purchase storage temperature to a maximum of $3^{\circ} \mathrm{C}$

${ }^{1} \mathrm{~S}_{\mathrm{R}}$ represents time (h) for yogurt cups to leave production facility and arrive at retail facility.

${ }^{2} \mathrm{~S}_{\mathrm{C}}$ represents time (h) that yogurt cups are at retail facility until purchased by consumer.

The importance of the distribution chain for controlling microbial contaminants has also been demonstrated for other refrigerated foods (Pradhan et al., 2010). For example, a listeriosis risk assessment estimated that reducing storage time from retail to consumer from 28 to $16 \mathrm{~d}$ would reduce the mean number of listeriosisassociated deaths per year by 24 to $57 \%$, depending on the retail-meat formulation [with or without growthinhibitors (Pradhan et al., 2010)]. Our results indicate that improved data on the production to retail supply chain, as well as possibly a refined model that separates this time into (1) warehouse storage and (2) transportation time, could further improve model estimates, particularly if accurate estimates on initial contamination frequency are available.

\section{Monte Carlo Models Provide Estimates of Effect of Interventions on Mold Spoilage}

The Monte Carlo simulation model developed here also provides the opportunity to assess how different interventions can reduce consumer exposure to visible mold spoilage, using so-called what-if scenarios. Whereas modeling the effect of using a protective culture would seem a logical what-if scenario to evaluate with this model, this scenario would have provided limited insights, as both protective cultures used here reduced visible mold spoilage to an undetectable level (none of the inoculated yogurts formulated with protective cultures showed visible mold growth). As a proof of concept, we thus selected 2 scenarios for what-if analyses (Table 5). The first scenario evaluated was the effect of a shortened distribution chain (i.e., having a regionally distributed yogurt) on consumer exposure to visible mold. This scenario involved changes in 2 parameters, based on expert opinion from a smaller regional yogurt processor, including (1) shortening the time from production to retail and (2) increasing the retail case storage time (presumably reflecting reduced product turnover as compared to more popular national brands).
These changes had a minimal effect on the number of consumers exposed to visible mold, with an estimate of $532 \pm 24.3$ consumers exposed to visible mold per 1 million cups of yogurt produced (versus $550 \pm 25.2$ consumer exposures in the base model; Figure 5). Whereas these results suggest limited changes in outcome when the simulated distribution chain was changed to reflect a specific smaller regional yogurt manufacturer, specific facilities that use this model should collect and use data specific to their supply chain (in addition to an accurate estimate of initial contamination rates) in order to provide the most accurate outcome estimates.

The second what-if scenario run here assessed the effect of lowering the storage temperature of yogurt throughout the distribution chain. For this what-if scenario, we (1) limited the maximum storage temperature

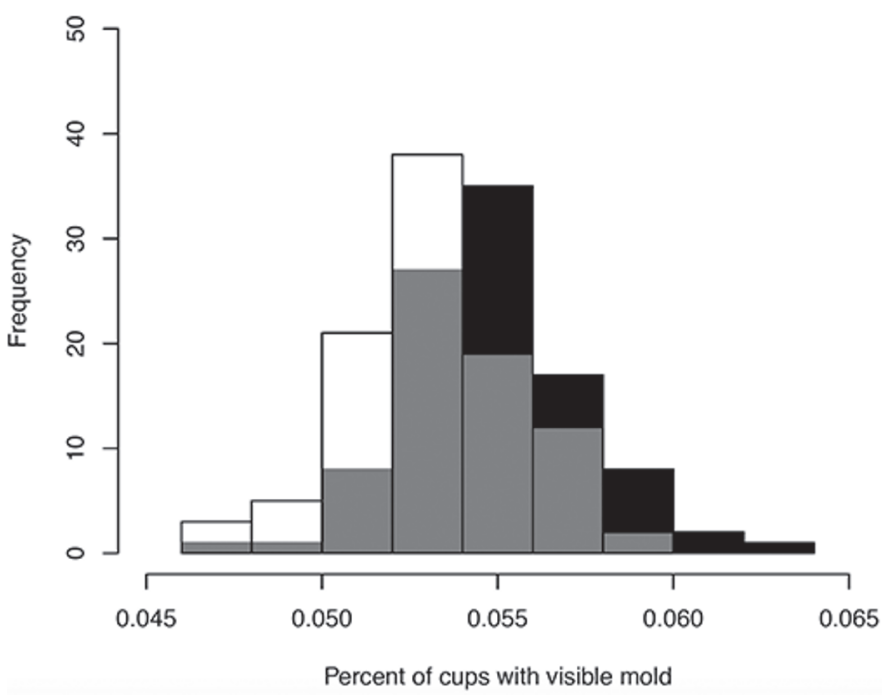

Figure 5. Histograms of the simulated percent of consumers exposed to visible mycelium mold growth in yogurt per 1 million cups of yogurt produced using distribution parameters typical for a nationally distributed yogurt (black) compared to yogurt produced using distribution parameters typical for a regionally distributed yogurt (white). The area shaded in gray represents where the 2 histograms overlap. 
from production to consumer purchase to $3^{\circ} \mathrm{C}$ and (2) lowered the mean domestic refrigerator temperature by $2^{\circ} \mathrm{C}$. These changes, when applied in combination, lowered the mean number of consumers exposed to visible mold growth to $538 \pm 25.9$ consumers per 1 million cups of yogurt produced (Table 5; Figure 6). Importantly, these two what-if scenarios showed limited effects on the outcome (i.e., consumer exposure to visible mold) when different changes to the distribution chain were simulated, which is consistent with our sensitivity analysis, which showed that initial contamination rate had the largest effect on outcomes. Whereas storage and distribution temperatures close to $0^{\circ} \mathrm{C}$ may reduce consumer exposure to visible mold, these scenarios were not modelled here, as they were (1) deemed unrealistic and (2) would require more specific data on mold growth at extremely low temperatures, particularly because some studies show that certain molds including Penicillium can grow at temperatures as low as $-4^{\circ} \mathrm{C}$ (Mislivec and Tuite, 1970).

Overall, our data support that, in addition to the use of preservatives or protective cultures, reducing initial mold contamination represents the most effective approach to reducing mold spoilage. Reducing initial contamination levels, however, typically requires a number of specific approaches and strategies that differ in the contributions to reducing mold contamination between processing facilities and even within processing facilities (e.g., between days or seasons). Key strategies to reducing mold contamination include good manufacturing practices, validated sanitation standard operating procedures, air-filtration systems, and aseptic packaging conditions (Sofos, 1993; Salustiano et al., 2003; Tamime and Robinson, 2007). For example, a study in a yogurt processing facility in Brazil reported a significant decrease in the yeast and mold counts following implementation of good manufacturing practices and sanitation standard operating procedures (Cusato et al., 2013). This processing facility specifically reported that food handler training led to substantial changes in food handlers' behavior towards food quality; most food handlers did not understand basic routes of contamination before system implementation (Cusato et al., 2013). Airborne transmission of mold spores also plays an important role in mold contamination in the processing facility. Hence, implementation of air-filtration systems in the filling areas or use of enclosed filling cabinets supplied with high-efficiency particulate air-filtered air represent key strategies to reduce mold contamination (Nauth, 2004). The microbiological quality of packaging materials also plays a role in contamination levels in the processing facility. Sterilizing packaging materials before they are filled with product could help lower the

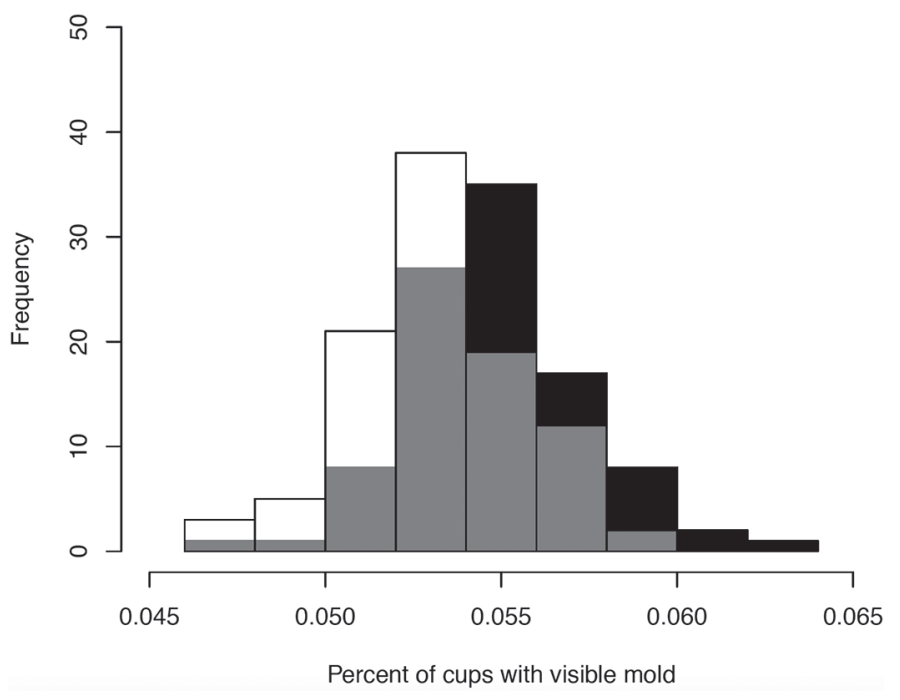

Figure 6. Histograms of the simulated percent of consumers exposed to visible mycelium mold growth in yogurt per 1 million cups of yogurt produced assuming no change in storage temperature over shelf-life of yogurt (black) compared to lowering the storage temperature (white), applied in combination by (1) lowering the mean domestic refrigerator temperature by $2^{\circ} \mathrm{C}$ and (2) limiting the production to consumer purchase storage temperature to a maximum of $3^{\circ} \mathrm{C}$. The area shaded in gray represents where the 2 histograms overlap.

initial contamination rate as well. Further research on the reduction of the initial contamination rate that each of these interventions achieves is needed to fully assess which measure to employ as well as an evaluation of facility-specific design concerns. Due to the complexity of mold transmission in processing facilities and the associated complexity of interventions, implementation of specific environmental control strategies could not be assessed with our Monte Carlo simulation model and would require considerably more complex agent-based models.

\section{CONCLUSIONS}

Our study provides a set of data and tools that will be valuable as the dairy industry is faced with external pressures (e.g., the clean label trend) that require novel approaches to control spoilage and in particular fungal spoilage of yogurt. Whereas our specific data suggest that the 2 commercially available protective cultures evaluated did not effectively control yeast growth at initial contamination levels of $10^{1} \mathrm{cfu} / \mathrm{g}$, this finding is not necessarily representative of all protective cultures. In addition, future efforts may yield other biopreservatives that can control both yeast and mold growth, as supported by some studies that reported characterization of lactic acid bacteria strains that inhibit both yeast and mold (Delavenne et al., 2013). The challenge 
study protocol and the Monte Carlo simulation model reported here will provide a valuable set of tools that can be used for evaluation of specific biopreservative strategies of interest, with the ability to quantify spoilage reduction through the use of simulation models with facility- and supply chain-specific input data. The simulation model should also be easily expandable to other organisms (e.g., yeast) and other dairy commodities where yeast and mold spoilage is a major concern (e.g., shredded cheese).

\section{ACKNOWLEDGMENTS}

The authors thank the staff of the Food Processing and Development Laboratory (Cornell University, Ithaca, NY) for help in yogurt production. This publication was made possible through a gift from Chobani Inc. (New Berlin, NY), supporting innovative research in dairy quality. We thank them for their generous contribution and commitment to food innovation and quality.

\section{REFERENCES}

Atanassova, M. R., C. Fernández-Otero, P. Rodríguez-Alonso, I. Fernández-No, J. Garabal, and J. Centeno. 2016. Characterization of yeasts isolated from artisanal short-ripened cows' cheeses produced in Galicia (NW Spain). Food Microbiol. 53:172-181.

Baert, K., F. Devlieghere, L. Bo, J. Debevere, and B. De Meulenaer. 2008. The effect of inoculum size on the growth of Penicillium expansum in apples. Food Microbiol. 25:212-217.

Beletsiotis, E., D. Ghikas, and K. Kalantzi. 2011. Incorporation of microbiological and molecular methods in HACCP monitoring scheme of molds and yeasts in a Greek dairy plant: A case study. Procedia Food Sci. 1:1051-1059.

Bokulich, N. A., and D. A. Mills. 2013. Facility-specific "house" microbiome drives microbial landscapes of artisan cheesemaking plants. Appl. Environ. Microbiol. 79:5214-5223.

Buehler, A. J., R. Evanowski, N. Martin, K. Boor, and M. Wiedmann. 2017. Internal transcribed spacer (ITS) sequencing reveals considerable fungal diversity in dairy products. J. Dairy Sci. 100:88148825 .

Burgain, A., M. Bensoussan, and P. Dantigny. 2013. Effect of inoculum size and water activity on the time to visible growth of Penicillium chrysogenum colony. Int. J. Food Microbiol. 163:180-183.

Chandan, R. C., and K. R. O'Rell. 2013. Manufacture of various types of yogurt. Pages 263-295 in Manufacturing Yogurt and Fermented Milks. Ramesh C. Chandan and A. Kilara, ed. John Wiley \& Sons Inc., Ames, IA.

Cheong, E. Y., A. Sandhu, J. Jayabalan, T. T. K. Le, N. T. Nhiep, H. T. M. Ho, J. Zwielehner, N. Bansal, and M. S. Turner. 2014. Isolation of lactic acid bacteria with antifungal activity against the common cheese spoilage mould Penicillium commune and their potential as biopreservatives in cheese. Food Control 46:91-97.

Crowley, S., J. Mahony, and D. van Sinderen. 2013a. Broad-spectrum antifungal-producing lactic acid bacteria and their application in fruit models. Folia Microbiol. (Praha) 58:291-299.

Crowley, S., J. Mahony, and D. van Sinderen. 2013b. Current perspectives on antifungal lactic acid bacteria as natural bio-preservatives. Trends Food Sci. Technol. 33:93-109.

Cusato, S., A. H. Gameiro, C. H. Corassin, A. S. Sant'Ana, A. G. Cruz, J. A. F. Faria, and C. A. F. de Oliveira. 2013. Food safety systems in a small dairy factory: Implementation, major challenges, and assessment of systems' performances. Foodborne Pathog. Dis. 10:6-12.
Davidson, P. M., T. M. Taylor, and S. E. Schmidt. 2013. Chemical preservatives and natural antimicrobial compounds. Pages 765801 in Food Microbiol. American Society of Microbiology Press, Washington, DC

Delavenne, E., R. Ismail, A. Pawtowski, J. Mounier, G. Barbier, and G. Le Blay. 2013. Assessment of lactobacilli strains as yogurt bioprotective cultures. Food Control 30:206-213.

Devlieghere, F., L. Vermeiren, and J. Debevere. 2004. New preservation technologies: Possibilities and limitations. Int. Dairy J. $14: 273-285$.

Dyer, R., J. Frank, B. Johnson, and P. Hickey. 2004. Microbiological tests for equipment, containers, water, and air. Pages 325-340 in Standard Methods for Examination of Dairy Products 17 ed. American Public Health Association, Washington, DC.

EcoSure. 2007. EcoSure 2007 cold temperature database. Accessed Oct. 15, 2017. http://foodrisk.org/exclusives/EcoSure.

Frisvad, J. C., and R. A. Samson. 2004. Polyphasic taxonomy of Penicillium subgenus Penicillium. A guide to identification of food and air-borne terverticillate penicillia and their mycotoxins. Stud. Mycol. 49:1-174.

Garnier, L., F. Valence, and J. Mounier. 2017a. Diversity and control of spoilage fungi in dairy products: An update. Microorganisms $5: 42$.

Garnier, L., F. Valence, A. Pawtowski, L. Auhustsinava-Galerne, N. Frotté, R. Baroncelli, F. Deniel, E. Coton, and J. Mounier. 2017b. Diversity of spoilage fungi associated with various French dairy products. Int. J. Food Microbiol. 241:191-197.

Garofalo, C., E. Zannini, L. Aquilanti, G. Silvestri, O. Fierro, G. Picariello, and F. Clementi. 2012. Selection of sourdough lactobacilli with antifungal activity for use as biopreservatives in bakery products. J. Agric. Food Chem. 60:7719-7728.

Gerez, C. L., M. I. Torino, G. Rollán, and G. Font de Valdez. 2009. Prevention of bread mould spoilage by using lactic acid bacteria with antifungal properties. Food Control 20:144-148.

Gougouli, M., K. Kalantzi, E. Beletsiotis, and K. P. Koutsoumanis. 2011. Development and application of predictive models for fungal growth as tools to improve quality control in yogurt production. Food Microbiol. 28:1453-1462.

Gougouli, M., and K. P. Koutsoumanis. 2010. Modelling growth of Penicillium expansum and Aspergillus niger at constant and fluctuating temperature conditions. Int. J. Food Microbiol. 140:254-262.

Gougouli, M., and K. P. Koutsoumanis. 2017. Risk assessment of fungal spoilage: A case study of Aspergillus niger on yogurt. Food Microbiol. 65:264-273.

Holzapfel, W. H., R. Geisen, and U. Schillinger. 1995. Biological preservation of foods with reference to protective cultures, bacteriocins and food-grade enzymes. Int. J. Food Microbiol. 24:343-362.

Jacques, N., and S. Casaregola. 2008. Safety assessment of dairy microorganisms: The hemiascomycetous yeasts. Int. J. Food Microbiol. 126:321-326.

Koutsoumanis, K. 2001. Predictive modeling of the shelf life of fish under nonisothermal conditions. Appl. Environ. Microbiol. 67:18211829.

Kure, C. F., I. Skaar, and J. Brendehaug. 2004. Mould contamination in production of semi-hard cheese. Int. J. Food Microbiol. 93:41-49.

Kure, C. F., Y. Wasteson, J. Brendehaug, and I. Skaar. 2001. Mould contaminants on Jarlsberg and Norvegia cheese blocks from four factories. Int. J. Food Microbiol. 70:21-27.

Lačanin, I., J. Mounier, A. Pawtowski, M. Dušková, J. Kameník, and R. Karpíšková. 2017. Assessment of the antifungal activity of Lactobacillus and Pediococcus spp. for use as bioprotective cultures in dairy products. World J. Microbiol. Biotechnol. 33:188.

Lambertini, E., J. Barouei, D. W. Schaffner, M. D. Danyluk, and L. J. Harris. 2017. Modeling the risk of salmonellosis from consumption of pistachios produced and consumed in the United States. Food Microbiol. 67:85-96.

Lavoie, K., M. Touchette, D. St-Gelais, and S. Labrie. 2012. Characterization of the fungal microflora in raw milk and specialty cheeses of the province of Quebec. Dairy Sci. Technol. 92:455-468. 
Ledenbach, L. H., and R. T. Marshall. 2009. Microbiological spoilage of dairy products. Pages 41-67 in Compendium of the Microbiological Spoilage of Foods and Beverages. Springer, New York, NY.

MacBean, R. D. 2009. Packaging and the shelf life of yogurt. Pages 147-148 in Food Packaging and Shelf Life: A Practical Guide. G. L. Robertson, ed. CRC Press, Boca Raton, FL.

Mayoral, M. B., R. Martín, A. Sanz, P. E. Hernández, I. González, and T. García. 2005. Detection of Kluyveromyces marxianus and other spoilage yeasts in yoghurt using a PCR-culture technique. Int. J. Food Microbiol. 105:27-34.

Mislivec, P. B., and J. Tuite. 1970. Temperature and relative humidity requirements of species of Penicillium isolated from yellow dent corn kernels. Mycologia 62:75-88.

Muhialdin, B. J., Z. Hassan, and S. K. Sadon. 2011. Antifungal activity of Lactobacillus fermentum Te007, Pediococcus pentosaceus Te010, Lactobacillus pentosus G004, and L. paracasi D5 on selected foods. J. Food Sci. 76:M493.

Nauth, K. R. 2004. Yogurt. Page 158 in Handbook of Food and Beverage Fermentation Technology. Vol. 134. Y. H. Hui, L. MeunierGoddik, J. Josephsen, W.-K. Nip, and P. S. Stanfield, ed. CRC Press, New York, NY.

Pang, H., E. Lambertini, R. L. Buchanan, D. W. Schaffner, and A. K Pradhan. 2017. Quantitative microbial risk assessment for Escherichia coli O157: H7 in fresh-cut lettuce. J. Food Prot. 80:302-311.

Penney, V., G. Henderson, C. Blum, and P. Johnson-Green. 2004. The potential of phytopreservatives and nisin to control microbial spoilage of minimally processed fruit yogurts. Innov. Food Sci. Emerg. Technol. 5:369-375.

Pitt, J. I., and A. D. Hocking. 2009. Fungi and Food Spoilage. 3 ed. Springer, New York, NY.

Pradhan, A. K., R. Ivanek, Y. T. Gröhn, R. Bukowski, I. Geornaras, J. N. Sofos, and M. Wiedmann. 2010. Quantitative risk assessment of listeriosis-associated deaths due to Listeria monocytogenes contamination of deli meats originating from manufacture and retail. J. Food Prot. 73:620-630.

Pradhan, A. K., R. Ivanek, Y. T. Gröhn, I. Geornaras, J. N. Sofos, and M. Wiedmann. 2009. Quantitative risk assessment for Listeria monocytogenes in selected categories of deli meats: Impact of lactate and diacetate on listeriosis cases and deaths. J. Food Prot. 72:978-989.

Quelch, J. A., and S. B. Ash. 1980. Consumer satisfaction with food products. Food Policy 5:313-318.

R Core Team. 2013. R: A Language and Environment for Statistical Computing. R Foundation for Statistical Computing, Vienna, Austria.

Radha, K., and L. S. Nath. 2014. Studies on the air quality in a dairy processing plant. Indian J. Vet. Anim. Sci. 43:346-353.

Richins, M. L., and B. J. Verhage. 1985. Seeking redress for consumer dissatisfaction: The role of attitudes and situational factors. J. Consum. Policy 8:29-44.
Rosso, L., J. Lobry, and J. Flandrois. 1993. An unexpected correlation between cardinal temperatures of microbial growth highlighted by a new model. J. Theor. Biol. 162:447-463.

Salustiano, V. C., N. J. Andrade, S. C. C. Brandão, R. M. C. Azeredo, and S. A. K. Lima. 2003. Microbiological air quality of processing areas in a dairy plant as evaluated by the sedimentation technique and a one-stage air sampler. Braz. J. Microbiol. 34:255-259.

Samson, R. A., J. Houbraken, U. Thrane, J. C. Frisvad, and B. Andersen. 2010. Detection and isolation of indoor fungi. Pages 10-19 in Food and Indoor Fungi. CBS-KNAW Fungal Biodiversity Centre, Utrecht, the Netherlands.

Sathe, S. J., N. N. Nawani, P. K. Dhakephalkar, and B. P. Kapadnis. 2007. Antifungal lactic acid bacteria with potential to prolong shelf-life of fresh vegetables. J. Appl. Microbiol. 103:2622-2628.

Schaffner, D. W., J. McEntire, S. Duffy, R. Montville, and S. Smith 2003. Monte Carlo simulation of the shelf life of pasteurized milk as affected by temperature and initial concentration of spoilage organisms. Food Prot. Trends 23:1014-1021.

Schnürer, J., and J. Magnusson. 2005. Antifungal lactic acid bacteria as biopreservatives. Trends Food Sci. Technol. 16:70-78.

Snyder, A. B., J. J. Churey, and R. W. Worobo. 2016. Characterization and control of Mucor circinelloides spoilage in yogurt. Int. J. Food Microbiol. 228:14-21.

Sofos, J. N. 1993. Current microbiological considerations in food preservation. Int. J. Food Microbiol. 19:87-108.

Stiles, M. E. 1996. Biopreservation by lactic acid bacteria. Antonie van Leeuwenhoek 70:331-345.

Suriyarachchi, V. R., and G. H. Fleet. 1981. Occurrence and growth of yeasts in yogurts. Appl. Environ. Microbiol. 42:574-579.

Tamime, A. Y., and R. K. Robinson. 2007. Background to manufacturing practice. Pages 118-120 in Yoghurt: Science and Technology. Elsevier, Boca Raton, FL.

Temelli, S., S.. Anar, C. Sen, and P. Akyuva. 2006. Determination of microbiological contamination sources during Turkish white cheese production. Food Control 17:856-861.

Vacheyrou, M., A.-C. Normand, P. Guyot, C. Cassagne, R. Piarroux, and Y. Bouton. 2011. Cultivable microbial communities in raw cow milk and potential transfers from stables of sixteen French farms. Int. J. Food Microbiol. 146:253-262.

Vangay, P., E. B. Fugett, Q. Sun, and M. Wiedmann. 2013. Food microbe tracker: a web-based tool for storage and comparison of food-associated microbes. J. Food Prot. 76:283-294.

Zink, D. L. 1997. The impact of consumer demands and trends on food processing. Emerg. Infect. Dis. 3:467.

Zwieterin, M. H., and S. Van Gerwen. 2000. Sensitivity analysis in quantitative microbial risk assessment. Int. J. Food Microbiol $58: 213-221$. 